\title{
First-principles study to explore the possibility of inducing martensitic transformation in ordered B2 TiRu phase by alloying with Pd
}

\author{
BS Ngobe, MJ Phasha, IA Mwamba \\ Advanced Materials Division (AMD), MINTEK, 200 Malibongwe Drive, Randburg 2125, South Africa \\ Email: Bonganing@mintek.co.za, MajeP@mintek.co.za
}

\begin{abstract}
Density functional theory (DFT) based on the first-principles technique, CASTEP, was used to explore the possibility of inducing martensitic transformation (MT) in a stable B2 TiRu alloy by systematic introduction of palladium (Pd) on the ruthenium (Ru) site. The structural, mechanical and electronic properties of pure, as well as, Pd-doped TiRu were calculated. The elastic constants obtained show that the addition of Pd seems to induce MT in the ordered TiRu, as shown by mechanical instability $\left(C^{\prime}=C_{11}\right.$ - $\left.C_{12}<0\right)$ of the B2 phase against shear deformation at $0 \mathrm{~K}$. This is an indication that $\mathrm{B} 2$ is likely to transform to low symmetry phases such as $\mathrm{L} 1_{0} / \mathrm{B} 19 /$ B19'. Moreover, the calculated total density of states (T-DOS) also indicated that the addition of Pd shifted the Fermi level $\left(E_{F}\right)$ from the centre of the pseudogap of the ordered pure TiRu towards the right (anti-bonding region), rendering the resulting B2 ternary phase unstable at certain Pd compositions higher than 10 atomic percent (at.\%). The predicted induced martensitic transformation is one of the key characteristics of shape memory behaviour in B2 Ti-based alloys such as NiTi, TiPd and TiPt. Further work on the possible low temperature phases resulting from B2 Ti-Ru-Pd ternary alloys is underway.
\end{abstract}

Keywords: DFT-based first-principles technique, elastic properties, electronic structure, martensitic transformation (MT)

\section{Introduction}

Titanium (Ti) is an important engineering material for components of various applications ranging from biomedical, aerospace and automotive industries, ${ }^{1,2}$ where the high strength to weight ratio and high resistance to corrosion render $\mathrm{Ti}$ and its alloys attractive and ideal. ${ }^{1}$ Ti-based intermetallic compounds are promising materials for high temperature applications as structural (heat and corrosion resistance) or non-structural materials (electronic devices, superconductors, etc.). ${ }^{1,3,4,5}$

Addition of platinum-group metals (PGMs) to several alloys produced commercial alloys over the past 4-5 decades for the purpose of improving corrosion resistance and other functional properties. ${ }^{6,7}$ Being noble and high temperature stability enables PGMs as candidates of choice for high temperature structural application. Such materials find use in automotive exhaust system and in the manufacturing of high quality glass and glass fibres industries as they present high corrosion and oxidation resistance [8]. Among the PGMs, ruthenium ( $\mathrm{Ru})$ is the cheapest and the most reactive, hence it receives most of its application in chemical and electronics industries as alloying agent due to its excellent catalytic activity. ${ }^{9-11}$ If added in Ti and other super alloys such as those applied in aerospace industry, Ru improved the corrosion resistance as well as chemical and electrical stability at higher temperatures. ${ }^{12,13}$

Common to all PGMs is that they form a B2 (austenite) phase with $\mathrm{Ti}$ at high temperature and at compositions closer to 50:50 atomic percent (at.\%). For most PGMs, the B2 phase transforms in a diffusionless manner (martensitically) on cooling to orthorhombic or tetragonal intermetallic phases. ${ }^{14,15}$ This martensitic transformation is one of the key characteristics for shape memory behaviour, which makes them potential materials for high temperature shape memory alloys (HTSMAs) if it occurs above $100^{\circ} \mathrm{C}$, earmarked for possible application in aerospace engines. However, only the phase stability of B2 TiRu phase is maintained to room temperature, hence it is not listed among PGM-based potential HTSMA materials despite its cost benefits. ${ }^{10,11,16}$ This highly stable B2 phase behaviour is also found in other transition metals belonging to group VIII of the periodic table of elements. ${ }^{16-19}$

Upon comprehensive study of the Ti-Ru system, Murray ${ }^{20}$ reported that the equiatomic TiRu binary compound crystallizes in the B2type crystal structure with space group Pm-3m of an ordered body centered cubic (BCC) CsCl-type. ${ }^{17,18,21}$ This B2 phase is a sole high temperature intermetallic phase of the TiRu system with lattice parameter ranging from 3.06 to $3.076 \AA$, and it undergoes congruent melting at $2130^{\circ} \mathrm{C}$. CsCl-type titanium intermetallic compounds are currently the most attractive hydrogen storage materials. ${ }^{22}$ Experimental work at MINTEK on the equiatomic TiRu alloy found that this B2 phase is brittle. ${ }^{23}$

The TiPd binary alloys have been widely used in severe, corrosive services in the chemical process industries. ${ }^{24}$ Moreover, there is a strong interest in TiPd alloys due to their interesting mechanical properties and technological importance for engineering and medicine, in particular for the shape memory effect and for the property of reversible hydrogen storage. ${ }^{25}$ However, with the market price of Pd metal has been rising over the past few years, ${ }^{11}$ which renders Pd selection for such industries unattractive. One of the noted reasons hampering the industrial use of PGM based 
Ti SMAs is the high cost, therefore the focus of this work was on finding a relatively cheaper alternative alloy. The systematic introduction of up to 25 at.\% $\mathrm{Pd}$ on the $\mathrm{Ru}$ site is aimed to reduce the stability of B2 TiRu phase to the point where this B2 phase transform to a lower temperature phase such as B19 orthorhombic (found in TiAu, TiPd and TiPt), B19' monoclinic (found in NiTi) or $\mathrm{L1}_{0}$ tetragonal (found in IrTi) accompanied by shape memory effects (SME). ${ }^{14,15,26-28}$

This work also observed the atomistic and the $a b$ initio modelling work carried out by other researchers while acknowledging that there is still limited literature available on equiatomic Ti-Ru ${ }^{10,16,20,21,29,30}$ and ternary Ti-Pd-Ru alloys. ${ }^{29}$ Diale et al. ${ }^{29}$ employed supercell (SC) approach to study the effect of Ru on B2 $\mathrm{Ti}_{50} \mathrm{Pd}_{50}$ with a composition change of 6.25 at. \% steps using VASP. It is well known that shape memory behaviour is very sensitive to composition change, ${ }^{31}$ hence the current choice of approach that allows smaller composition variations.

In this work, a density functional theory based on virtual crystal approximation (VCA) solid-solution unit cell approach is used to investigate the Pd alloying effect on phase stability and elastic properties of the ordered B2 equiatomic TiRu phase with smaller composition changes of 2.5 at. \% steps ${ }^{28,32}$ to represent B2 (1-x) TiRu-(x) TiPd solid solutions. This approach was carried out with the objective to induce martensitic transformation in a stable B2 TiRu phase.

\section{Methodology}

The calculations were performed using DFT - based plane-waves pseudopotential code CASTEP as implemented in Materials Studio software, ${ }^{33}$ with the projector augmented wave (PAW). ${ }^{34}$ The electron-exchange and correlation were described by the PerdewBurke-Ernzerhof (PBE) functional of the generalized gradient approximation (GGA). ${ }^{35}$ An energy cut-off of $500 \mathrm{eV}$, and k-points of $13 \times 13 \times 13$ were used, and were found to be sufficient to converge the total energy of the $\mathrm{B} 2 \mathrm{Ti}_{50} \mathrm{Ru}_{50-\mathrm{x}} \mathrm{Pd}_{\mathrm{x}}$ alloys with $\mathrm{x}$ ranging from $0,2.5,5,7.5,10,15,25$ and 50 at. \%.

All the equilibrium crystal structures were obtained via geometry optimization in the Brayden-Fletcher-Goldfarb-Shanno (BFGS) minimization scheme. ${ }^{36}$ The convergence criterion of less than $1 \times 10^{-5} \mathrm{eV} /$ atom, the maximum residual forces of $0.03 \mathrm{eV} / \AA$, maximum residual bulk stress of $0.05 \mathrm{GPa}$ and maximum atomic displacement of $1 \times 10^{-3} \AA$ were utilized to achieve reasonable accuracy. The elastic constants were computed from optimized crystal structure for each composition.

\subsection{Phase stability}

The stability of any compound can be deduced from the heats of formation commonly known as enthalpy of formation $H_{f}{ }^{37}$ and it is used to determine the thermodynamic stability of phases. A phase is thermodynamically stable if $H_{f}$ is found to be negative, else the phase becomes less thermodynamically stable if less negative or unstable if found to be positive. ${ }^{38}$ This stability property is expressed in Equation 1,
$H_{f}=\left\{\frac{1}{2} E_{\text {Tot }}^{T i_{50} R u_{50-x} P d_{x}}-x E_{\text {solid }}^{T i}-(1-x) E_{\text {solid }}^{R u_{50-x} P d_{x}}\right\}$

where, $E_{T o t}^{T i_{50} R u_{50-x} P d_{x}}$ is the calculated total energy of the intermetallic phase, $E_{\text {solid }}^{T i}$ and $E_{\text {solid }}^{R u_{50-x} P d_{x}}$ are total energies of the pure elements or solid-solutions in their stable ground-state crystal structures, respectively, while $x$ and $(1-x)$ refer to the fractional composition of the constituent elements.

\subsection{Elastic and mechanical properties}

Elastic constants of solid materials provide a link between the mechanical and dynamical behaviour of crystals, and give important information about bonding characteristics at the equilibrium state. ${ }^{39,40}$ Other physical properties such as anisotropy factor, hardness, ductility and other important mechanical properties can be calculated from the elastic constants. The elastic stiffness constants ( $\mathrm{ij}=1,2,3,4,5$ and 6 ), forming a $6 \times 6$ symmetric tensor matrix, determine the response of the strain to external forces that can be obtained by applying a set of finite homogeneous deformations to a unit cell and by optimizing the internal atomic freedoms to calculate the stresses. ${ }^{41} \mathrm{~B} 2$ is a cubic system consisting of the simplest form of a stiffness matrix, where the number of independent elastic constants are reduced to three $\left(C_{11}, C_{12}\right.$ and $\left.C_{44}\right)$ in the Voigt notation, and the expression for shear elastic constants $C^{\prime}$ is shown in Equation 2.

$$
C^{\prime}=\frac{C_{11}-C_{12}}{2}
$$

According to Born-Huang's lattice dynamical theory, ${ }^{42,43}$ the mechanical stability criteria for B2 cubic crystals can be determined by satisfying the criteria given by a set of expressions in Equation 3.

$C_{11}>0, C_{44}>0, C_{11}-C_{12}>0, C_{11}+2 C_{12}>0$.

The crystal mechanical stability decreases when approaching the martensitic transition temperature, where the tetragonal shear modulus $\left(C^{\prime}\right)$ becomes much smaller than the monoclinic shear constant $\left(C_{44}\right)$ which represents the stiffness of the crystal against shear. ${ }^{44}$ The Zener anisotropic factor $(A)$ is given as the ratio of $C_{44}$ to $C^{\prime}$ and it is equal to 1 for isotropic crystals. Some of the mechanical properties determined from the computed elastic constants include the bulk modulus $(B)$, trigonal shear modulus $(G)$, Young's modulus $(E)$ and the Poisson's ratio $(v) .{ }^{10,16,21,29,30}$ In all crystal structures, the polycrystalline elastic modulus can be estimated from their set of independent elastic constants by two approximation methods, i.e. the Voigt (V) method which is the upper bound and the Reuss (R) method which is the lower bound as shown by a set of expressions given in Equation 4 for cubic crystal structures.

$$
\begin{aligned}
& B_{V}=B_{R}=\frac{1}{3}\left(C_{11}+2 C_{12}\right), G_{V}= \\
& \frac{1}{5}\left(C_{11}-C_{12}+3 C_{44}\right) \text { and } G_{R}=\frac{\left(C_{11}-C_{12}\right) C_{44}}{4 C_{44}+3\left(C_{11}-C_{12}\right)} .
\end{aligned}
$$

The arithmetic average of the Voigt and Reuss is called the VoigtReuss-Hill (VHR) average. Thus the average shear $\left(G_{H}\right)$ and bulk $\left(B_{H}\right)$ modulus can be calculated using the set of expressions in Equation 5, including the average Young's modulus $(E)$ and the Poisson's ratio $(v)$ of the polycrystalline materials: 
$G_{H}=\frac{G_{V}-G_{R}}{2}, B_{H}=\frac{B_{V}-B_{R}}{2}, E=\frac{9 B_{H} G_{H}}{3 B_{H}+G_{H}}$ and $v=0.5\left(\frac{3 B_{H}-2 G_{H}}{3 B_{H}+G_{H}}\right)$

The relationship between the interatomic bonding and the physical properties can be considered using Pugh's $(B / G)$ and Poisson's $(v)$ ratios. Pugh's ratio which is used to describe the brittleness and ductility of metals, while the hardness is defined as the resistance of a material to external mechanical pressure. Vickers hardness $\left(H_{V}\right)$ is usually used in first-principles calculations ${ }^{45}$ to measure the resistance of solids to plastic or permanent deformation. The expression employed to determine the $H_{V}$ is shown in Equation 6 .

$H_{V}=0.92(k)^{1.137} \times G^{0.708}$,

where, $k=\frac{G}{B}$ is the inverse of Pugh's modulus ratio.

The first-principles calculations are considered as novel method for micro-investigation at the atomic scale to study the physical properties of solids.

\subsection{Electronic properties}

The study of electronic structures through the density of states (DOS) provides insights about the formation of alloys, and their phase stability. ${ }^{46}$ The DOS of a system describes how dense the states are populated per energy level. ${ }^{47}$ A DOS of zero at Fermi level $\left(E_{F}\right)$ means that the states are empty, rendering the material an insulator ${ }^{48}$ due to the unavailability of electrons in the conduction band. In intermetallic compounds, there exists a pseudogap at the Fermi level $\left(E_{F}\right)$ of the DOS spectra that determines the stability of the compound. If the constituent metals are able to form an ordered intermetallic phase which is stable at low temperature, the $E_{F}$ falls at the centre of the pseudogap, whereas if the ordered phase forms but is only stable at high temperature then the $E_{F}$ cuts on the shoulder of the DOS peak, indicating instability of the phase at 0 $\mathrm{K}$. Thus high DOS at $E_{F}$ is considered to be related to the structural instability. ${ }^{49}$ And taking into account that at the anti-bonding region the DOS values are higher, the phase having high transition temperature will undergo structural reconfiguration to minimize the higher energy indicated by $N\left(E_{F}\right)$. Consequently, those systems with higher energy in the anti-bonding region will undergo MT and hence have potential to exhibit the SME.

Thus, the electronic properties of the investigated alloys were determined from the TDOS spectra obtained from the optimised structures in terms of stability. They were also compared with those of TiPd and TiNi that are well known to possess the SME. ${ }^{17,18}$

\section{Results and discussion}

\subsection{Structural properties and enthalpies of formation}

The B2 cubic crystal structures of $\mathrm{TiRu}, \mathrm{Ti}_{50} \mathrm{Ru}_{50-\mathrm{x}} \mathrm{Pd}_{\mathrm{x}}$ and TiPd used in this work are shown in Fig. 1, while the obtained equilibrium lattice parameters of the investigated alloys as well as their corresponding calculated enthalpies of formation are presented in Table 1. As shown in Table 1, the predicted lattice parameters of pure and alloyed B2 phases were found to be within the acceptable error margin of $3 \%$ and in agreement with previous works. ${ }^{10,23,25,29,50}$ The lattice parameter of the investigated ternaries $\left(\mathrm{Ti}_{50} \mathrm{Ru}_{50-\mathrm{x}} \mathrm{Pd}_{\mathrm{x}}\right)$ slightly increases with $\mathrm{Pd}$ addition. This is expected since $\mathrm{Pd}$ atom has a larger atomic radius than $\mathrm{Ru}$ atom.

The calculated $H_{f}$ show that the B2 TiRu phase is the most thermodynamically stable compared to TiPd and TiNi, with TiNi found to be the least stable. These values were compared with available data and found to be in good agreement. ${ }^{16}$ It is interesting to note that heat of formation for $\mathrm{B} 2 \mathrm{Ti}_{50} \mathrm{Ru}_{50-\mathrm{x}} \mathrm{Pd}_{\mathrm{x}}$ increased with addition of $\leq 7.5$ at.\% $\mathrm{Pd}$, but at $\mathrm{Pd}$ composition above 7.5 at.\% decreased $H_{f}$ signifying reduced stability. The observation at $\mathrm{Pd} \leq 7.5$ at. $\%$ is in contrast to that of Diale et al, whereas at Pd $>7.5$ at.\% is in agreement, though their results show a strong linear trend. ${ }^{29}$

Table 1: Optimised structural models and formation enthalpies of the investigated B2 alloys

\begin{tabular}{|c|c|c|c|c|c|}
\hline \multirow{2}{*}{ Phases } & \multicolumn{2}{|c|}{$\begin{array}{c}\text { Lattice Parameters, } \\
\mathbf{a}(\mathbf{\AA})\end{array}$} & \multirow[b]{2}{*}{$\mathbf{V}\left(\AA^{3}\right)$} & \multicolumn{2}{|c|}{$\Delta H_{\mathrm{f}}(\mathrm{eV} / \mathrm{atom})$} \\
\hline & GGA & Literature & & GGA & Literature \\
\hline TiNi & 3.059 & 3.015 & 28.62 & -0.351 & - \\
\hline $\mathrm{TiRu}$ & 3.097 & $3.087^{10,21}$ & 29.7 & -0.819 & $0.743^{16}$ \\
\hline $\mathrm{Ti}_{50} \mathrm{Ru}_{47.5} \mathrm{Pd}_{2.5}$ & 3.097 & - & 29.71 & -0.853 & - \\
\hline $\mathrm{Ti}_{50} \mathrm{Ru}_{45} \mathrm{Pd}_{5}$ & 3.099 & - & 29.75 & -0.837 & - \\
\hline $\mathrm{Ti}_{50} \mathrm{Ru}_{42.5} \mathrm{Pd}_{7.5}$ & 3.101 & - & 29.84 & -0.82 & - \\
\hline $\mathrm{Ti}_{50} \mathrm{Ru}_{40} \mathrm{Pd}_{10}$ & 3.104 & - & 29.92 & -0.802 & - \\
\hline $\mathrm{Ti}_{50} \mathrm{Ru}_{35} \mathrm{Pd}_{15}$ & 3.114 & - & 30.19 & -0.765 & - \\
\hline $\mathrm{Ti}_{50} \mathrm{Ru}_{25} \mathrm{Pd}_{25}$ & 3.151 & - & 31.29 & -0.725 & - \\
\hline TiPd & 3.227 & $3.17^{29}$ & 33.6 & -0.373 & $0.519^{16,25}$ \\
\hline
\end{tabular}

\subsection{Elastic constants and mechanical properties}

The calculated elastic constants and deduced elastic moduli results of the investigated alloys are presented in Fig. 2. Fig. 2(a) shows

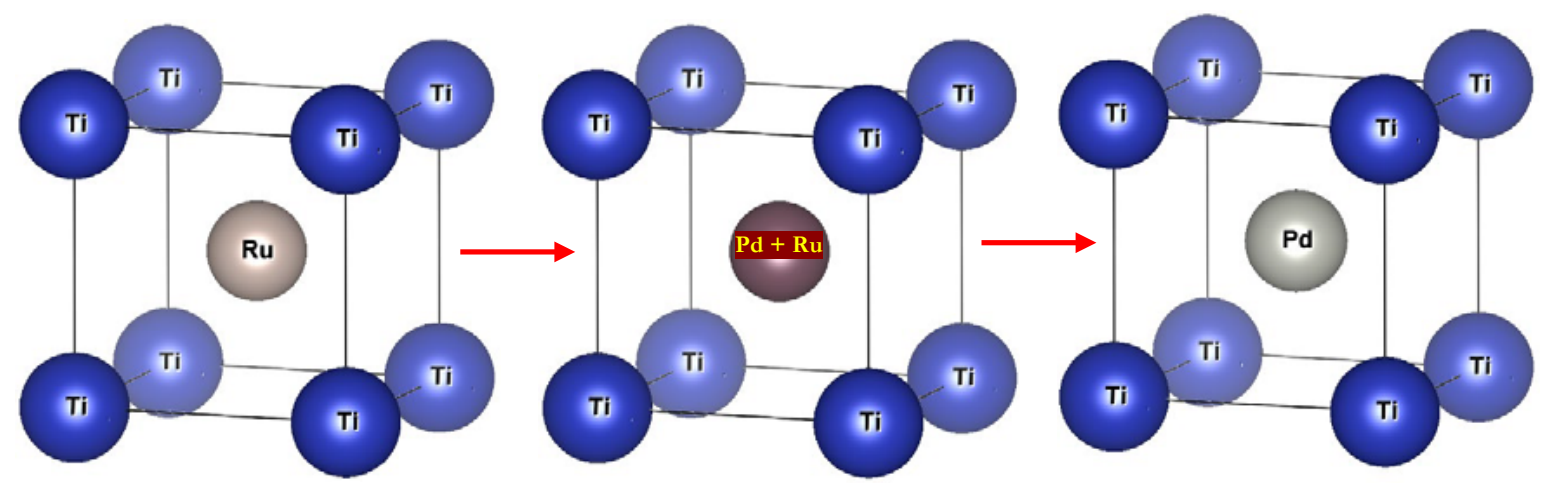

Figure 1: Crystal structure models of $\mathrm{B} 2 \mathrm{TiRu}, \mathrm{Ti}_{50}-\mathrm{Ru}_{50-\mathrm{x}} \mathrm{Pd}_{\mathrm{x}}$ and TiPd compositions used in the calculations 
that the calculated elastic constants of B2 TiRu met the mechanical stability criterion set in Equation 3 for cubic crystals. However, this criteria was not satisfied for B2 TiPd, which indicates its mechanical instability at $0 \mathrm{~K}$. Substituting some Ru atoms with Pd in pure TiRu, gradually decreased $C_{11}$ and $C_{44}$ while, $C_{12}$ and $C_{P}$ increased up to 15 at.\% Pd. It is between 10 and 15 at.\%, where the mechanical stability criteria was broken $\left(C_{11}<C_{12}\right)$, and rendered the $\mathrm{B} 2$ phases unstable, which could be associated with a potential martensitic transition of a lower temperature phase with possibility of SME. Pettifor et al. ${ }^{39,51}$ stated that materials with metallic bonds become ductile if it has larger positive Cauchy pressure $\left(C_{P}\right)$, suggesting that the predicted ternary compositions would be more ductile than pure B2 TiRu. The metallicity of the B2 TiRu was found to strongly increase when more Pd atoms substitute $\mathrm{Ru}$ atoms and the $\mathrm{Ti}_{50} \mathrm{Ru}_{35} \mathrm{Pd}_{15}$ alloy had the highest metallic bonding and hence most ductility as indicated by the highest $C_{P}$ amongst the investigated alloys.

The elastic modulus properties such as $B, G, E$ and $H_{V}$ are important in determining the strength of materials, and these results are shown in Fig. 2(b). The $G, E$ and $H_{V}$ decreased significantly, while $B$ decreased gradually on adding up to 15 at. $\% \mathrm{Pd}$, and above this composition, $E$ and $H_{V}$ remained almost constant whereas $B$ dropped significantly.

Jain et al. ${ }^{10}$ stated that higher Young's modulus $(E)$ is associated with covalent or ionic bonds. Therefore, the larger $E$ the harder the material to deform, whereas the smaller $E$ the easier the materials to deform. The pure TiRu phase was found to have a higher value of $E(316.2 \mathrm{GPa})$ indicating rigidity, while the $\mathrm{Ti}_{50} \mathrm{Ru}_{25} \mathrm{Pd}_{25}$ had the lowest $E$ amongst the investigated ternary compositions. Therefore, these compositions are expected to deform plastically, resulting in lower hardness as predicted. In many cases, the compound with high $H_{V}$ has large $G$, indicating that the hardness of materials is more sensitive to shear modulus than to bulk modulus. ${ }^{40,52}$

To further characterize the ductility of the crystal structures, the Pugh's and Poisson's ratios were also evaluated. The determined Poisson's ratio $v$, the classical Pugh's modulus ratio $B / G$, tetragonal shear modulus $\left(C^{\prime}\right)$ and elastic anisotropy $(A)$ of the investigated compositions are presented in Fig. 3. The $A, v$ and $B / G$ increased with increased Pd while shear modulus $C^{\prime}$ and $H_{V}$ decreased, at least up to 15 at.\%.

The results obtained showed that addition of Pd yielded some ductility to $\mathrm{B} 2 \mathrm{TiRu}$. These results predict that at Pd compositions just above 10 at. $\%$, the $\mathrm{B} 2$ phase becomes mechanically unstable as opposed to above 25 at. \% as predicted by Diale et al. ${ }^{29}$ The $\mathrm{Ti}_{50} \mathrm{Ru}_{50-\mathrm{x}} \mathrm{Pd}_{\mathrm{x}}$ ternary compositions were found to be ductile, since their $B / G$ was above 1.75 threshold value. ${ }^{53,54}$ Although the Pugh's ratio of TiRu was in compliance with Pugh's criteria for ductility, it is suggested for the first time here that a new factor be considered to predict increased ductility of B2 cubic crystals: the ratio of trigonal shear modulus $(G)$ to tetragonal shear moduli $\left(C^{\prime}\right)$. For easy plastic shearing to occur $G / C$ 'must be greater than 1 , and in this work, this criteria was satisfied in alloys containing $\geq 10$ at. $\% \mathrm{Pd}$. It is likely that this particular shearing criterion is responsible for martensitic transformation in known B2 Ti-X shape memory alloys.
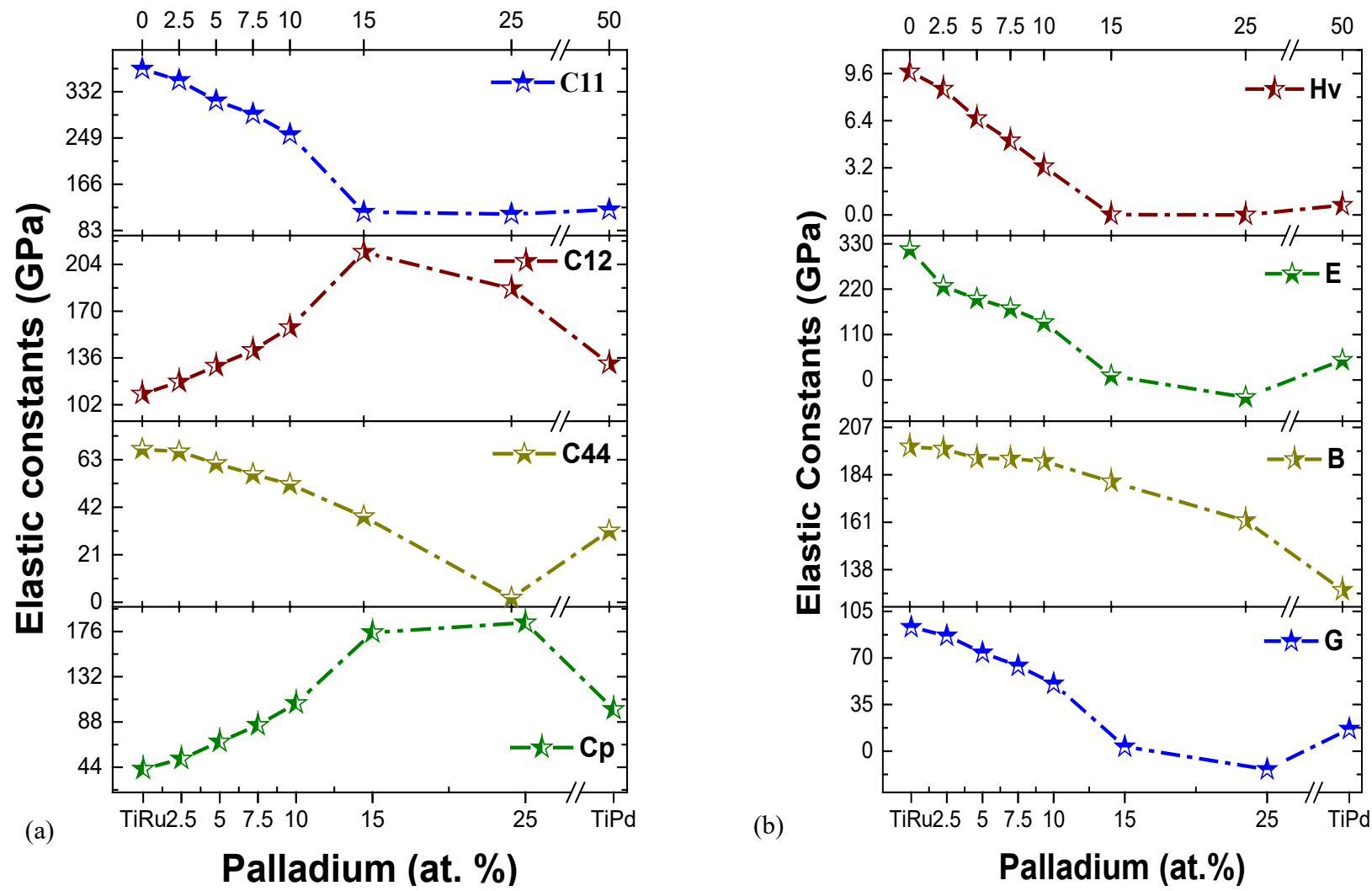

Figure 2: Cubic crystal independence elastic constants $\mathrm{C}_{11}, \mathrm{C}_{12}, \mathrm{C}_{44}, \mathrm{C}_{\mathrm{P}}$ and the elastic modulus of the investigated $\mathrm{B} 2 \mathrm{Ti}_{50} \mathrm{Ru}_{50-\mathrm{x}} \mathrm{Pd}_{\mathrm{x}}$ compositions 


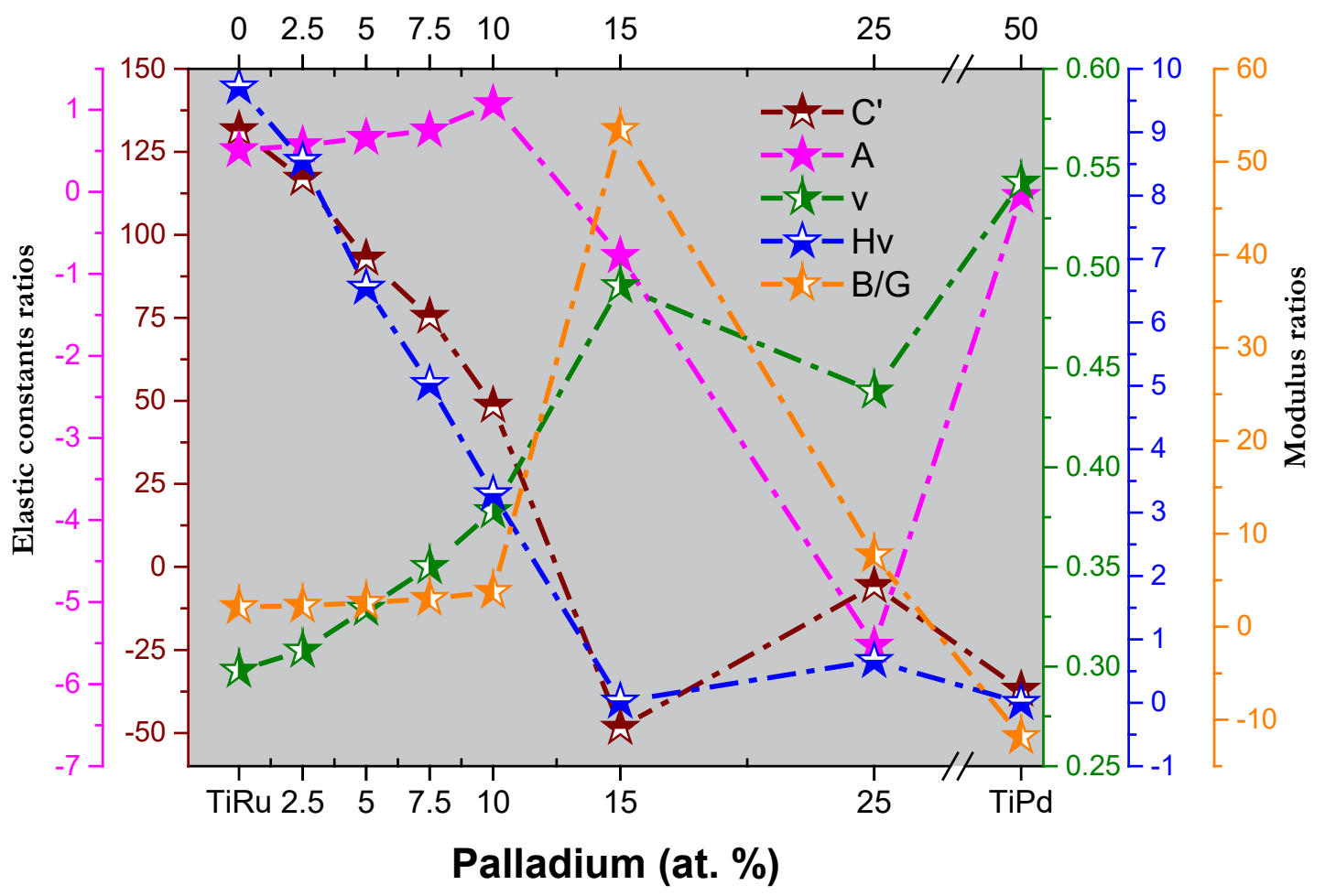

Figure 3: Elastic moduli ratios, shear modulus $C^{\prime}$ and corresponding $\mathrm{H}_{\mathrm{V}}$ of the investigated $\mathrm{B} 2$ compositions

In addition, Frantsevich's rule states that the ductility or brittleness of a material can also be determined in terms of its Poisson ratio $(v)$, and provides information about the bonding of materials. ${ }^{55}$ Frantsevich's rule suggests that if $v$ is closer to $1 / 3$, the material will be ductile (consist of metallic bonds), otherwise the material will be brittle (consist of covalent or ionic bonds) with ratios much smaller than 1/3.48,54,55 Fig. 3 shows that the calculated $v$ for the ternary compositions were more ductile as they possess stronger metallic bonds, having $v>0.333$. The ordered TiRu was expected to possess some covalent bond characteristics with its $v<0.298$.

\subsection{Electronic properties}

The electronic structure and chemical bonding characteristics of the investigated $\mathrm{B} 2 \mathrm{Ti}_{50} \mathrm{Ru}_{50-\mathrm{x}} \mathrm{Pd}_{\mathrm{x}}$ compositions are presented in
Fig. 4 with those of B2 TiNi and TiPd for comparison. The total densities of states (TDOS) for the investigated alloys were nonzero across the Fermi level $\left(E_{F}\right)$, indicating that the plain B2 TiRu and $\mathrm{B} 2 \mathrm{Ti}_{50} \mathrm{Ru}_{50-\mathrm{x}} \mathrm{Pd}_{\mathrm{x}}$ compositions were mainly characterised by metallic bonds. The TDOS values at $E_{F}$ were $0.52,1.17,1.66,1.23$, $1.25,3.18,3.40,2.25$ and $2.15 / \mathrm{eV}$ for $\mathrm{Pd}$ compositions ranging from $0,2.5,5,7.5,10,15,25,50$ at. $\%$ and $\mathrm{TiNi}$, respectively. Again, the $\mathrm{Ti}_{50} \mathrm{Ru}_{35} \mathrm{Pd}_{15}$ composition had the highest metallicity, correlating to the highest $B / G$ and $C_{P}$.

Fig. 4 shows that the conduction and valence band coincide perfectly, resulting in a deep valley around the Fermi level of TDOS for B2 TiRu, signifying that this phase is thermodynamically stable at $0 \mathrm{~K}$ and without a phase transformation. Thus, B2 TiRu does not

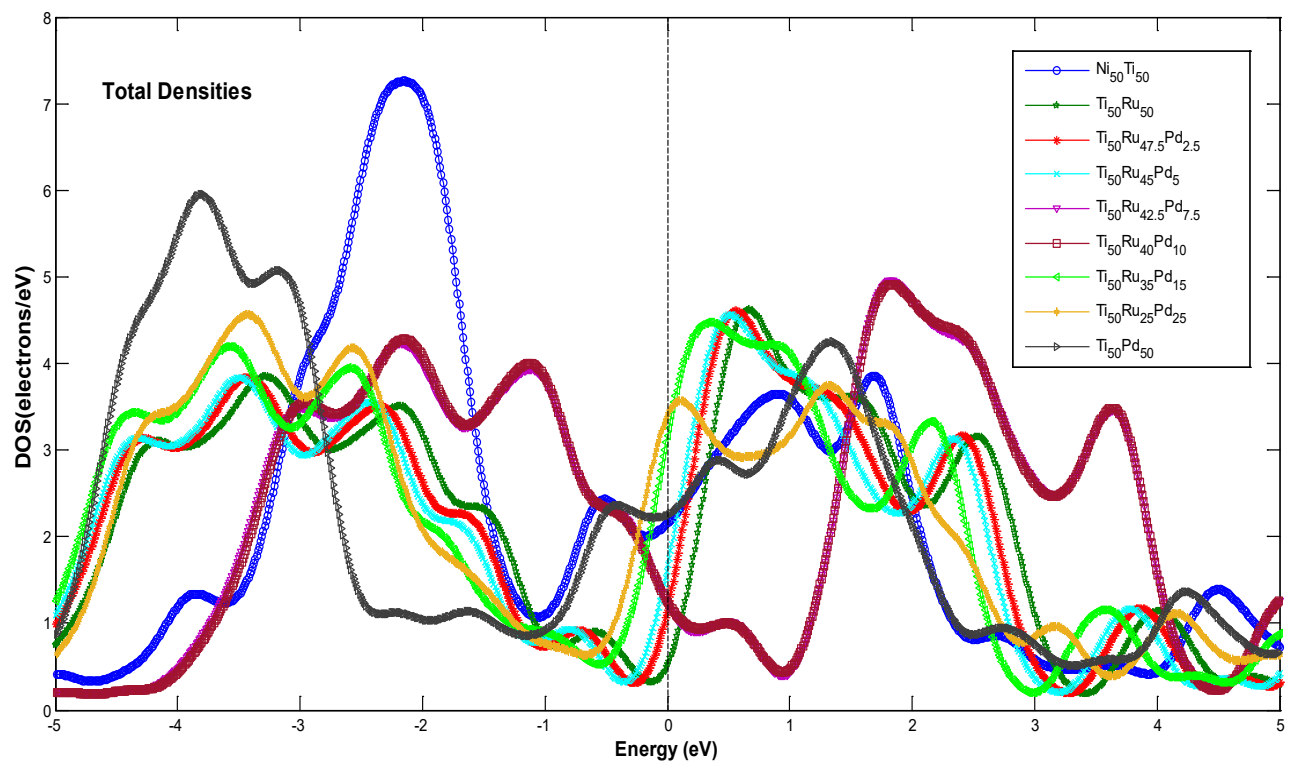

Figure 4: Total densities (TDOS) of $\mathrm{B} 2 \mathrm{TiNi}$ and $\mathrm{Ti}_{50} \mathrm{Ru}_{50-\mathrm{x}} \mathrm{Pd}_{\mathrm{x}}(\mathrm{x}=0,2.5,5,7.5,10,15,25$ and 50 at. \%) compositions 
exhibit SME at room temperature, since SMAs usually show $E_{F}$ cutting on the shoulder of TDOS curve above the pseudogap. ${ }^{56}$ However, introducing $\mathrm{Pd}$ on $\mathrm{Ru}$ site, shifted the deep-valley towards the conduction band with $E_{F}$ cutting on the shoulder of TDOS curve. This indicate that adding Pd induces instability in B2 TiRu, enabling it to potentially exhibits the SME and hence be considered as a potential SMA, in agreement with the previous study. ${ }^{29}$ Furthermore, the higher DOS values seems to signal higher transition temperature as can be seen in B2 TiPd, with high possibility to undergo MT and subsequently exhibit SME.

\section{Conclusions}

For ternary compositions above 10 at. $\% \mathrm{Pd}$, the mechanical stability criteria is broken $\left(C_{11}<C_{12}\right)$, rendering the $\mathrm{B} 2$ phase unstable, which can be associated with a potential martensitic transition to a lower temperature phase, with the possibility to possess SME. This study proposes for the first time a new factor to be taken into consideration when predicting increased ductility of B2 cubic crystals: the ratio of trigonal shear modulus $(G)$ to tetragonal shear moduli $\left(C^{\prime}\right)$ to be greater than 1 . In agreement with mechanical stability predictions, the DOS results also revealed that adding Pd induced instability in B2 TiRu, suggesting that these alloys could be considered as potential SMAs with SME.

\section{Acknowledgements}

This paper is published with the permission of MINTEK. The authors would like to thank the Advanced Metals Initiative (AMI) of the Department of Science and Innovation (DSI) for financial support. The gratitude is further extended to the Centre for HighPerformance Computing (CHPC) in Cape Town for allowing us to carry out the calculations using their remote computing resources.

\section{Contribution}

The authors contributed equally on project initiation with BSN carrying out calculations under MJP supervision. Both were equally involved in interpretation of results. IAM's contribution was mainly on the overall project scope and direction

\section{References}

1. Wadood, A., 2018. Titanium and Titanium Alloys. Higher Education Commission, 1-144.

2. Banerjee, D., Williams, J.C., 2013. Perspective on Titanium Science and Technology. Acta Materialia 61, 844-879.

3. Belosevic-Cavor, J., Vasil, K., Dragan T., 2015. Ab Initio Studies of the Structural, Elastic, Electronic and Thermal Properties of $\mathrm{NiTi}_{2}$ Intermetallic. Journal of Physics and Chemistry of Solids 85, 197-205.

4. Boehlert, C.J., Majumdar, B.S., Seetharaman, V., Miracle, D.B., 1999. Part I. The Microstructural Evolution in Ti-Al-Nb O + Bcc Orthorhombic Alloys. Metallurgical and Materials Transactions A 30(9), 2305-2323.

5. Ding, X. F., Lin, J. P., Zhang, L. Q., Su, Y.Q., Chen, G.L., 2012. Microstructural Control of TiAl-Nb Alloys by Directional Solidification. Acta Materialia 60(2), 498-506.

6. Semenova, E., 1997. Alloys with the Shape Memory Effect in Systems of d-Transition Metals Containing Metals of the Platinum Group. Powder Metallurgy and Metal Ceramic, 36 (7-8), 394-404.

7. Schutz, R.W., Kuang-O, Y., Porter, R.L., Spadafora, F.P., 2002. Process for Melting and Casting Ruthenium-Containing of IridiumContaining Titanium Alloys. US 2002/0189404 A1, 1-6.

8. Fischer, B., Behrends, D., Dietmar Freund, D., Lupton, D.F., Merker, J., 1999. High Temperature Mechanical Properties of the Platinum Group Metals. Platinum Metals Review 43 (1), 18-28.

9. Ornek, O., 2016. First-Principle Study of the Structural and Mechanical Properties of RuTi Compound. International Turkic World Conference on Chemical Science and Technologies, 66-67.
10. Jain, E., Pagare, G., Chouhan, S.S., Sanyal, P.S., 2014. Electronic Structure, Phase Stability and Elastic Properties of Ruthenium Based Four Intermetallic Compounds: Ab Initio Study. Intermetallics 59, 79-84.

11. Cowler, A., 2021. PGM Market Report. Johnson Matthey. Accessed June 28, 2021. https://matthey.com/-/media/files/pgm-market-report/ jm-pgm-market-report-may-2021.pdf.

12. Cornish L.A., 2017. PGMs: A Cornucopia of Possible Applications. The Journal of Southern African Institute of Mining and Metallurgy, $117,969-974$

13. Hubkowska, K., Kubisztal. J., Pajak, M., Łosiewicz, B., Czerwinski, A., 2021. Effect of the Alloying Metal on the Corrosion Resistance of Pd-Rich Binary Alloys with Pt, Rh, and Ru in Sulfuric Acid. Materials 14 (2923), 1-13.

14. Donkersloot, H.C., Van Vucht, J.H.N., 1970. Martensitic Transformations in Gold-Titanium, Palladium-Titanium and PlatinumTitanium Alloys near the Equiatomic Composition. Journal of the Less Common Metals 20 (2), 83-91.

15. Biggs, T., Witcomb, M.J., Cornish, L.A., 1999. MartensiteType Transformations in Platinum Alloys. Materials Science and Engineering A273-275, 204-207.

16. Xing, W., Xing-Qui C., Dianzhong L., Yiyi L., Fu, C.L., Meschel, S.V., Xueyong D., 2012. First-Principles Studies of Structural Stabilities and Enthalpies of Formation of Refractory Intermetallics: $\mathrm{TM}$ and $\mathrm{TM}_{3}(\mathrm{~T}=\mathrm{Ti}, \mathrm{Zr}, \mathrm{Hf} ; \mathrm{M}=\mathrm{Ru}, \mathrm{Rh}, \mathrm{Pd}, \mathrm{Os}, \mathrm{Ir}, \mathrm{Pt})$. Intermetallics 28, 16-24.

17. Kulkova, S.E., Valujsky, D.V., 2001. The Investigation of Electronic Properties of Ti-Based Alloys. Journal de Physique IV, 53-58.

18. Kulkova, S.E., Valujsky D.V., Jai Sam Kim, J.M., Lee, G., Koo, Y.M., 2001. Electronic Structure of Binary and Ternary Ti-Based Shape-Memory Alloys. Solid State Communications 119, 619-623.

19. Yamabe-Mitarai, Y., Arockiakumar, R., Wadood, A., Suresh, K.S., Kitashima, T., Hara, T, Shimojo, M, Tasaki, W., Takahashi, M., Takahashi, S., Hosodah, H., 2015. Ti (Pt, Pd, Au) Based High Temperature Shape Memory Alloys. Materials Today: Proceedings 2S, S517-S522.

20. Murray, J.L., 1982. The Ru-Ti (Ruthenium-Titanium) System. Bulletin of Alloy phase Diagrams 3 (2), 216-221.

21. Kong, Z., Duan, Y., Peng, M., Qu, D., Bao, L., 2019. Theoretical Predictions of Thermodynamic and Electronic Properties of TiM (M=Fe, Ru and Os). Physica B: Condensed Matter 573, 13-21.

22. Edalati, K., Matsuda, J., Yanagida, A., Akiba, E., Horita, Z., 2014. Activation of TiFe for Hydrogen Storage by Plastic Deformation using Groove Rolling and High-Pressure Torsion: Similarities and Differences. International Journal of Hydrogen Energy 39, 15589-15594.

23. Ngobe, B., Mwamba, A., 2015. Microstructural Stability of Aged Equiatomic Titanium Ruthenium (TiRu) Alloys. Mintek Internal Report 42151, 1-27.

24. Ishii, M., Kaneko, M., Oda, T., 2003. Titanium and its Alloys as Key Materials for Corrosion Protection Engineering. Nippon Steel Technical Report 87, 49-56.

25. Chen, X.Q., Fu, C.L., Morris, J.R., 2010. The Electronic, Elastic, and Structural Properties of Ti-Pd Intermetallics and Associated Hydrides from First-Principles Calculations. Intermetallics 18, 998-1006.

26. Sanusi, K.O., Ayodele, O.L., Khan, M.T.E., 2014. A Concise Review of the Applications of NiTi Shape-Memory Alloys in Composite Materials. South African Journal of Science 110, 1-5.

27. Kibey, S., Sehitoglu, H., Johnson, D.D., 2009. Energy Landscape for Martensitic Phase Transformation in Shape Memory NiTi. Acta Materialia 57, 1624-1629.

28. Yamabe-Mitarai, Y., Hara, T., Phasha, M.J., Ngoepe, P.E., Chikwanda, H.K., 2012. Phase Transformation and Crystal Structure of IrTi. Intermetallics 31, 26-33.

29. Diale, R.G., Modiba, R., Ngoepe, P.E., Chauke, H.R., 2019. The Effect of Ru on Ti50Pd50 high Temperature Shape Memory Alloy: a First-Principles Study. Materials Research Society.

30. Gao, Y., Guo, C., Li, C., Cui, S., Du, Z., 2009. Thermodynamic Modeling of Ru-Ti System. Journal of Alloys and Compounds 479, $148-151$.

31. Frenzel, J., Wieczorek, A., Opahle, I., Maaß, B., Drautz, R., Eggeler, G., 2015. On the Effect of Alloy Composition on Martensite Start Temperatures and Latent Heats in Ni-Ti-Based Shape Memory Alloys. Acta Materialia 90, 213-231.

32. Phasha, M.J., Bolokang, A.S., Kebede, M.A., 2021. First-Principles Investigation of W-V- And W-Mo Alloys as Potential Plasma Facing Materials (PFMs) for Nuclear Applications. International Journal of Refractory Metals and hard Materials 95, 105448.

33. Segall, M.D., Lindan, P.J.D., Probert, M.J., Pickard, C.J., Hasnip, P.J., Clark, S.J, Payne, M.C., 2002. First-Principles Simulation: Ideas, 
Illustrations and the CASTEP Code. Journal of Physics: Condensed Matter 14, 2717-2744.

34. Blöchl, P.E., 1994. Projector Augmented-plane Wave Method. Physical Review B: 50 (24), 17953-17978.

35. Perdew, J.P., Wang, Y., 1992. Accurate and Simple Analytic Representation of the Electron-Gas Correlation Energy. Physical Review B: 45, 13244-13249.

36. Fischer, T.F., Almlof, J., 1992. General methods for geometry and wave function optimization. The Journal of Physical Chemistry 96, 9768-9774.

37. Raed, J., Mohammed Abu-Jafar, M., Abdelraziq, I., Mousa, A., Ouahrani, T., Khenata, R., 2018. Insight into the Structural, Electronic, Elastic and Optical Properties of the Alkali Hydride Compounds, XH $(\mathrm{X}=\mathrm{Rb}$ and $\mathrm{Cs})$. American Institute of Physics: Advances 045017 (8), $1-20$.

38. Yang, J., Huang, J., Ye, Z., Fan, D., Chen, S., Zhao, Y., 2017. First-Principle Calculations on Structural Energies of Cu-Ti Binary System Intermetallic Compounds in $\mathrm{Ag}-\mathrm{Cu}-\mathrm{Ti}$ and $\mathrm{Cu}-\mathrm{Ni}-\mathrm{Ti}$ Active Filler Metals. Ceramics International, 1-11.

39. Liu, S., Tang, C., Zhan, Y., 2016. Theoretical Prediction of Transition Metal Alloying Effects on the Lightweight TiAl Intermetallic. Metallurgical and Materials Transactions 47A, 1451-1459.

40. Wu, S.C., Fecher, G.H., Naghavi, S.S., Felser, C., 2019. Elastic Properties and Stability of Heusler Compounds: Cubic $\mathrm{Co}_{2} \mathrm{YZ}$ Compounds with L21 Structure. Journal of Applied Physics 125, 1-18.

41. Zhou, L., Su, K., Wang, Y., Zeng, Z., Li, Y., 2014. First-Principle Study of the Properties of $\mathrm{Li}, \mathrm{Al}$ and $\mathrm{Cd}$ doped Mg Alloys. Journals of Alloys and Compounds 596, 63-68.

42. Gomisa, O., Manjónb, F.J., Rodríguez-Hernándezc P., A. Muñozc, A., 2019. Elastic and Thermodynamic Properties of $\alpha-\mathrm{Bi}_{2} \mathrm{O}_{3}$ at High Pressures: Study of Mechanical and Dynamical Stability. Journal of Physics and Chemistry of Solids 124, 111-120.

43. Wagner, M.F.-X., Windl, W., 2008. Lattice Stability, Elastic Constants and Macroscopic Moduli of NiTi Martensites from First Principles. Acta Materialia 56, 6232-6245.

44. Sedlák, P., Janovská, M., Bodnárová, L., Heczko, O., Seiner, H., 2020. Softening of Shear Elastic Coefficients in Shape Memory Alloys near the Martensitic Transition: a Study by Laser-Based Resonant Ultrasound Spectroscopy. Metals 10 (1383), 1-13.
45. Yun-Fei, J., Xiang-Xi, Y, Jing-Tian, L., Wen-Xian, Z., Jun, Z., Xi-Jing, N., 2010. A Simple Theoretical Method to Predict the Hardness of Pure Metal Crystals. Chinese Physical Society 27 (7), 076201-1 to 076201-3.

46. Ravindran, P., Asokamani, R., 1997. Correlation between Electronic Structure, Mechanical Properties and Phase Stability in Intermetallic Compounds. Bulleting of Material Science 20 (4), 613-622.

47. Chowdhury, U.K., Rahman, $\mathrm{A}^{1}$., Rahman, $\mathrm{A}^{2}$., Bhuiyan, M.T.H., Ali, L., 2016. Ab initio Study on Structural, Elastic, Electronic and Optical Properties of Cuprate Based Superconductor. Condensed Matter Physics 3 (1231361), 1-10.

48. Chen, D., Chen, Z., Wu, Y., Wang, M., Ma, N., Wang, H., 2014 First-Principles Investigation of Mechanical, Electronic and Optical Properties of $\mathrm{Al}_{3} \mathrm{Sc}$ Intermetallic Compound under Pressure. Computational Materials Science 91, 165-172.

49. Gou, L., Liu, Y., Ng, T.E., 2014. An Investigation on the Crystal Structures of $\mathrm{Ti}_{50} \mathrm{Ni}_{50-\mathrm{x}} \mathrm{Cu}_{\mathrm{x}}$ Shape Memory Alloys Based on Density Functional Theory Calculations. Intermetallics 53, 20-25.

50. Sewak, R., Dey, C.C., 2019. Martensitic Phase Transformation in TiNi. Scientific Reports 9 (13500), 1-10.

51. Pettifor, D.G., 1992. Theoretical Predictions of Structure and Related Properties of Intermetallics. Materials Science and Technology 8 , 345-349.

52. Niu, H., Chen, X.Q., Liu, P., Xing, W., Cheng, X., Li, D., Li, Y., 2012. Extra-Electron Induced Covalent Strengthening and Generalization of Intrinsic Ductile-to-Brittle Criterion. Scientific Reports 718 (2), 1-6.

53. Pan, Y., Wen, M., Wang, L., Lin, Y.H., Guan, W.M., 2015. Iridium Concentration Driving the Mechanical Properties of IridiumAluminum Compounds. Journal of Alloys and Compounds 648, 771-777.

54. Ahmad, S.K., Gupta, D., 2016. Structural, Elastic and ThermoElectronic Properties of Paramagnetic Perovskite $\mathrm{PbTaO}_{3}$. Royal Society of Chemistry 6, 48009-48015.

55. Liu, L., Wu, X., Wang, R., Nie, X., He, Y., Zou, X., 2017. First-Principle Investigations on Structural and Elastic Properties of Orthorhombic TiAl under Pressure. Crystals 7 (111), 1-10.

56. Mahlangu, R., Phasha, M.J., Chauke, H.R., Ngoepe, P.E., 2013. Structural, Elastic and Electronic Properties of Equiatomic PtTi as Potential High-Temperature Shape Memory Alloys. Intermetallics. 27-32. 